See Article page 290.

\section{Commentary: Quacks like ischemia}

\author{
Thomas S. Maxey, MD
}

Aneurysms arising from any cardiac structure vary greatly and their natural history is not well known. Hongu and colleagues ${ }^{1}$ describe an interesting and unique case of idiopathic, left ventricular aneurysm diagnosed 6 years after an arterial switch and intracardiac baffle for double outlet right ventricle with transposition of the great arteries. The child was asymptomatic and the workup was thorough, including a cardiac catheterization and computed tomography scan. The ventricular aneurysm was noted in the infundibulum separating the mitral and neoaortic valve referred to as the ventriculo infundibular fold. As the authors note, this entity has been described in the aortomitral curtain or the intervalvular fibrosa and is usually associated with endocarditis but has not been reported in this type of conotruncal defect. ${ }^{2}$

The location of this particular aneurysm was in the myocardial infundibulum, not fibrosa. This location is relevant not only in the morphology of double outlet right ventricle, but also the fact ventricular aneurysms are severely scarred portions of infarcted myocardium that have lost contractility. I cannot help but think this finding was a direct result of the previous surgery, specifically ischemia. In double outlet defects with more of a side-byside orientation of the great vessels, the degree of coronary mobilization required is frequently more extensive than simple dextro-transposition of the great arteries. To achieve more extensive coronary mobilization, it is not uncommon to sacrifice a few small, proximal side branches. The authors state no branches were sacrificed during mobilization

From the Division of Cardiothoracic Surgery, Sanger Heart and Vascular Institute at Levine Children's Hospital, Atrium Health, Charlotte, NC.

Disclosures: The author reported no conflicts of interest.

The Journal policy requires editors and reviewers to disclose conflicts of interest and to decline handling or reviewing manuscripts for which they may have a conflict of interest. The editors and reviewers of this article have no conflicts of interest.

Received for publication June 26, 2020; revisions received June 26, 2020; accepted for publication June 27, 2020; available ahead of print June 30, 2020.

Address for reprints: Thomas S. Maxey, MD, Division of Cardiothoracic Surgery,

Sanger Heart and Vascular Institute, 1001 Blythe Blvd, Suite 300, Charlotte, NC

28203 (E-mail: thomas.maxey@atriumhealth.org).

JTCVS Techniques 2020;3:294

2666-2507

Copyright (c) 2020 The Authors. Published by Elsevier Inc. on behalf of The American Association for Thoracic Surgery. This is an open access article under the CC BY-NCND license (http://creativecommons.org/licenses/by-nc-nd/4.0/).

https://doi.org/10.1016/j.xjtc.2020.06.045

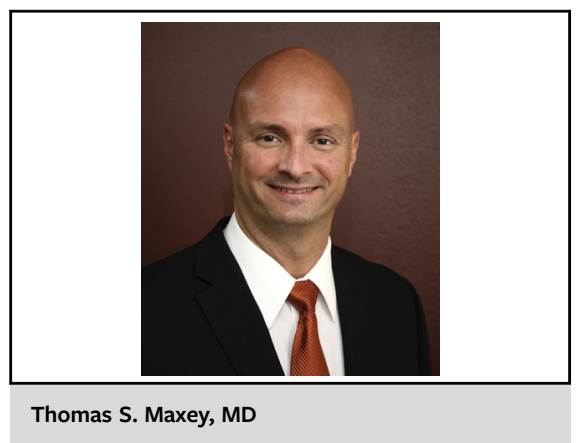

CENTRAL MESSAGE

Aneurysms of the left ventricle

are the result of focal ischemia.

Extensive mobilization of a cor-

onary button leads to some de-

gree of ischemia and could lead

to aneurysm formation.

of the left coronary button. Their subsequent description of the circumflex running directly over the aneurysmal mass helps solidify my suspicion of extensive mobilization of the left main coronary button likely resulting in focal ischemia. The previous repair did not have any muscle bundles resected nor was the ventricular septal defect enlarged to create a more favorable baffle to the neoaortic valve. There was no reported resection of any portion of the septum infundibulum, which could have weakened this area from focal ischemia leading to aneurysm formation.

Overall, this case report describes an entity that I have yet to encounter, although did find it interesting and insightful. Aneurysms of the left ventricle are the result of focal ischemia. Extensive mobilization of a coronary button leads to some degree of ischemia that we all frequently get away with secondary to adequate collateral circulation. The aneurysm in this case looks like ischemia, swims like ischemia, and quacks like ischemia. I try to never stray from the philosophy that most interesting surgical findings following surgery are related to surgery. The workup and treatment of this ventricular aneurysm were appropriate, and the authors should be commended because the child recovered well.

\section{References}

1. Hongu J, Yamagishi M, Maeda Y, Yaku H. Subaortic aneurysm after arterial switch operation for transposition type double outlet right ventricle. J Thorac Cardiovasc Surg Tech. 2020;3:290-3.

2. He D, Sinha P, Olivieri L, Jonas RA. Congenital aneurysm of the aortomitral intervalvular fibrosa. Ann Thorac Surg. 2015;99:314-6. 